\title{
Mechanical and electrochemical response in Surface treated low modulus biomedical alloy Ti-Nb-Ta-O
}

\author{
Srijan Acharya*, Shaurya Singh Dabas, Satyam Suwas, Kaushik Chatterjee \\ Department of Materials Engineering, Indian Institute of Science, Bangalore-560012, India. \\ *Corresponding Author: srijanacharya@gmail.com
}

\begin{abstract}
Surface modification of metallic biomedical implants are often performed using chemical or mechanical methods in order to make them more bio-active or resistant against surface-induced phenomena such as wear, corrosion or corrosion fatigue. In the present study, one such method, known as Surface Mechanical Attrition Treatment (SMAT), has been studied in terms of its effects on the mechanical and functional response of a newly developed low modulus metastable $\beta$ Ti-Nb-Ta-O alloy. The hardness of the surface was found to increase up to a certain duration of SMAT, due to increased degree of deformation on the surface. This was also supported by an increase in the peak broadening with respect to SMAT duration. Apart from surface hardening, SMAT also resulted in improvement of corrosion resistance of the Ti-Nb-Ta-O alloy due to formation of a more stable passive film.
\end{abstract}

Keywords: Ti-Nb-Ta-O, $\beta$ titanium, SMAT, surface modification, hardness, implants

\section{Introduction}

$\beta$-Titanium alloys consisting of elements like $\mathrm{Nb}, \mathrm{Ta}, \mathrm{Zr}$ are considered to replace conventional materials such as $\mathrm{cp}-\mathrm{Ti}$, Ti-6Al-4V alloys, stainless steel etc. for orthopedic implant applications. These alloys have elastic modulii (50-80 GPa) closer to that of the human bone (4-30 GPa) which make them less prone to failure caused by stress shielding effect, resulting from the modulus mismatch between implant material and human bone (4-30 GPA) [1, 2]. On the other hand, these alloying elements ( $\mathrm{Nb}, \mathrm{Ta}, \mathrm{Zr}$ ) have been reported to be less toxic than $\mathrm{V}, \mathrm{Al}, \mathrm{Cr}$, Ni etc [3]. The low elastic modulus of these alloys are known to be primarily caused by the stability of $\beta$-phase and an electron/atom (e/a) ratio 4.2-4.24. Moreover, the elements that are used as in the $\beta$ titanium alloys, such as $\mathrm{Nb}$, Ta, $\mathrm{Zr}$, have been found to be non-toxic for human body, unlike other elements such as Al, $\mathrm{V}$, Ni which are present in conventional implants [4]. Therefore, many new alloys pertaining to $\beta$-titanium alloy system has been developed in the past few decades, some of the popular compositions being Ti-13Nb-13Zr [5, 6], Ti-35Nb-7Zr-5Ta [7], Ti-29Nb-13Ta-4.6Zr [8,9]. Very recently, a Ti-34Nb-2Ta-0.50 alloy, with low elastic modulus and high strength, has been developed by the present authors $[10,11,12]$.

In addition to low elastic modulus and bio-compatibility, an implant material needs to possess adequate mechanical strength to impart high fatigue and wear resistance. However, properties such as fatigue and wear often depend upon the strength of the surface rather than the bulk material. Therefore, strengthening methods which involve hardening the surface rather than the whole material can offer promising results for this class of materials. Among different surface hardening methods, Surface mechanical Attrition Treatment (SMAT) has received much attention in the recent times. This method involves bombarding the surface of a material with hardened steel balls vibrating, generating a hardened casing on the surface [13]. SMAT leads to nano-crystallization on the surface by causing severe plastic deformation [14]. The process have been found to enhance the fatigue life by delaying crack initiation on the surface due to increase in the hardness and introducing compressive residual stresses [15]. In addition, there are reports on improvement in cell attachment and proliferation on several systems [16, 17]. However, most of the literature regarding effect of SMAT on mechanical, biological and corrosion behaviour has been centred on stainless steel and $\mathrm{cp}$-Ti. Similar systematic studies on $\beta$ titanium alloys are few in literature, though a positive influence of SMAT on corrosion behaviour of $\beta$ alloys has been reported [18].

In the present study, the surface hardening and corrosion behaviour of a Ti-Nb-Ta-O alloy subjected to SMAT has been investigated. The mechanical response after SMAT was checked by hardness studies which was supplemented with X-ray 
diffraction and microstructural characterization. The electrochemical behaviour of the material was analysed using the polarization study.

\section{Materials and Methods}

\subsection{Material and Processing}

Ti-34Nb-2Ta-0.50 alloys sheets of $\approx 5 \mathrm{~mm}$ thickness, obtained in hot rolled (above $\beta$-transus) condition, were cold rolled up to $70 \%$ thickness reduction and then annealed at $900^{\circ} \mathrm{C}$ for $0.5 \mathrm{~h}$ to obtain a uniform microstructure [10]. These annealed samples were then subjected to SMAT treatment at a frequency of $25 \mathrm{~Hz}$ for different durations of time, using a custom-designed SMAT unit (Cosmic Industrial Laboratories Limited, Bengaluru, India). The number of hardened steel balls used for the SMAT was 500 with each ball having a diameter of $4.75 \mathrm{~mm}$ each. The working distance between base of the chamber and sample surface was $20 \mathrm{~mm}$. Prior to SMAT treatment, the sample surfaces were mechanically polished up to P3000 paper followed by electropolishing at $40 \mathrm{~V}$ for $20 \mathrm{~s}$ using A3 solution in a Struers Lectropol-5 machine.

\subsection{Microstructural characterization}

The structural characterization of the samples was done primarily using X-ray diffraction. The X-ray diffraction patterns were recorded, before and after SMAT, on the normal plane of the samples. A PanAnalytical X'pert Pro X-ray diffractometer with Cu-Ka radiation was employed for this, where the patterns were recorded at a scan speed of $0.011^{\circ} / \mathrm{s}$.The microstructures were examined and recorded using both optical microscope (Zeiss) as well as a scanning electron microscope (ESEM, Quanta FEI). Transverse cross-sections of the samples were polished and then etched by Kroll's reagent $\left(2 \% \mathrm{HF}, 6 \% \mathrm{HNO}_{3}, 92 \% \mathrm{H}_{2} \mathrm{O}\right)$ for $30 \mathrm{~s}$, for microstructural examinations.

\subsection{Hardness measurement}

The surface hardness values of the annealed and SMAT-processes samples were measured on the by Micro-vickers indenter at an indentation load of $25 \mathrm{gf}$ with a dwell time $10 \mathrm{~s}$. The centre-to-centre distance between two indentations were kept more than five times the diagonal of each indentation.

\subsection{Corrosion studies}

The electrochemical performance of the Ti-Nb-Ta-O alloy before and SMAT processing was investigated in terms of polarization studies in a simulated body fluid (SBF) solution using a standard three electrode potentiostat (CHI604E, C.H. Instruments). Platinum wire was used as counter electrode and saturated calomel electrode (SCE) was used as reference. The SMAT-proccessed samples and non-SMAT electropolished samples were first cleaned by ultrasonic method and then were immersed in the solution for $3 \mathrm{~h}$ to obtain the open circuit potential. This was followed by polarization studies using tafel extrapolation at a scan rate of $2 \mathrm{x}$ $10^{-4} \mathrm{Vs}^{-1}$ with the voltage range between $-0.6 \mathrm{~V}$ to $+0.4 \mathrm{~V}$.

\section{Results and discussion}

\subsection{Microstructural features of the starting material}

The X-ray diffraction (XRD) pattern of the Ti-Nb-Ta-O alloy in as-received (AR) condition is shown in Fig.1, respectively. The XRD pattern consists of peaks from $\beta$-phase only. The AR sample was water quenched from $900^{\circ} \mathrm{C}$ after annealing, causing the retention of $\beta$ phase. Figure 2 shows optical microstructure of the AR sample which consists of equiaxed $\beta$-grains. The presence of $0.5 \mathrm{wt} \%$ oxygen leads to prevention of formation of $a$ " or $\omega$, which has been discussed in our previous study [10]. The average diameter of the $\beta$-grains were found to be $53 \pm 24 \mu \mathrm{m}$. 


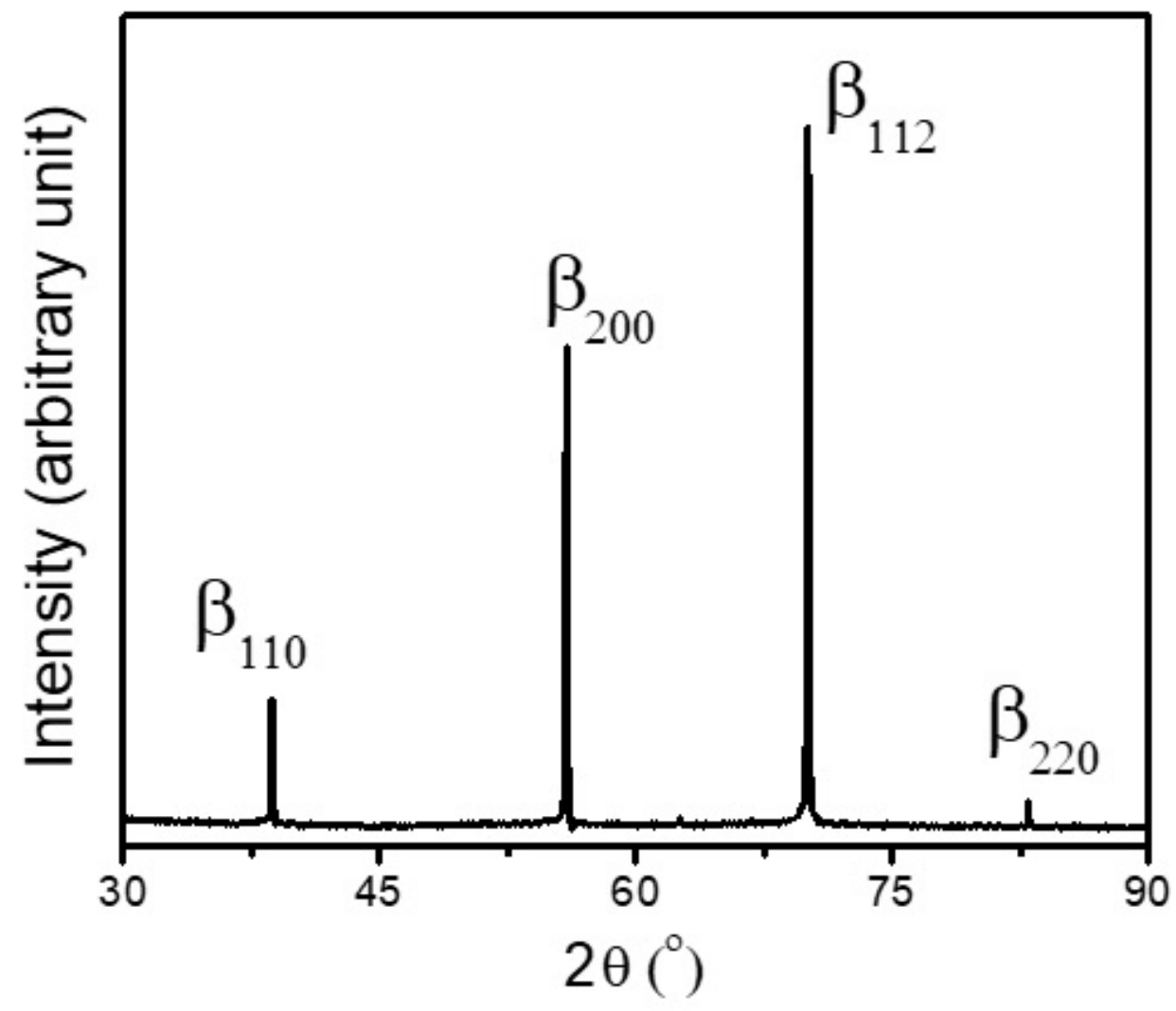

Fig. 1: X-ray diffraction pattern, showing peaks from $\beta$-phase

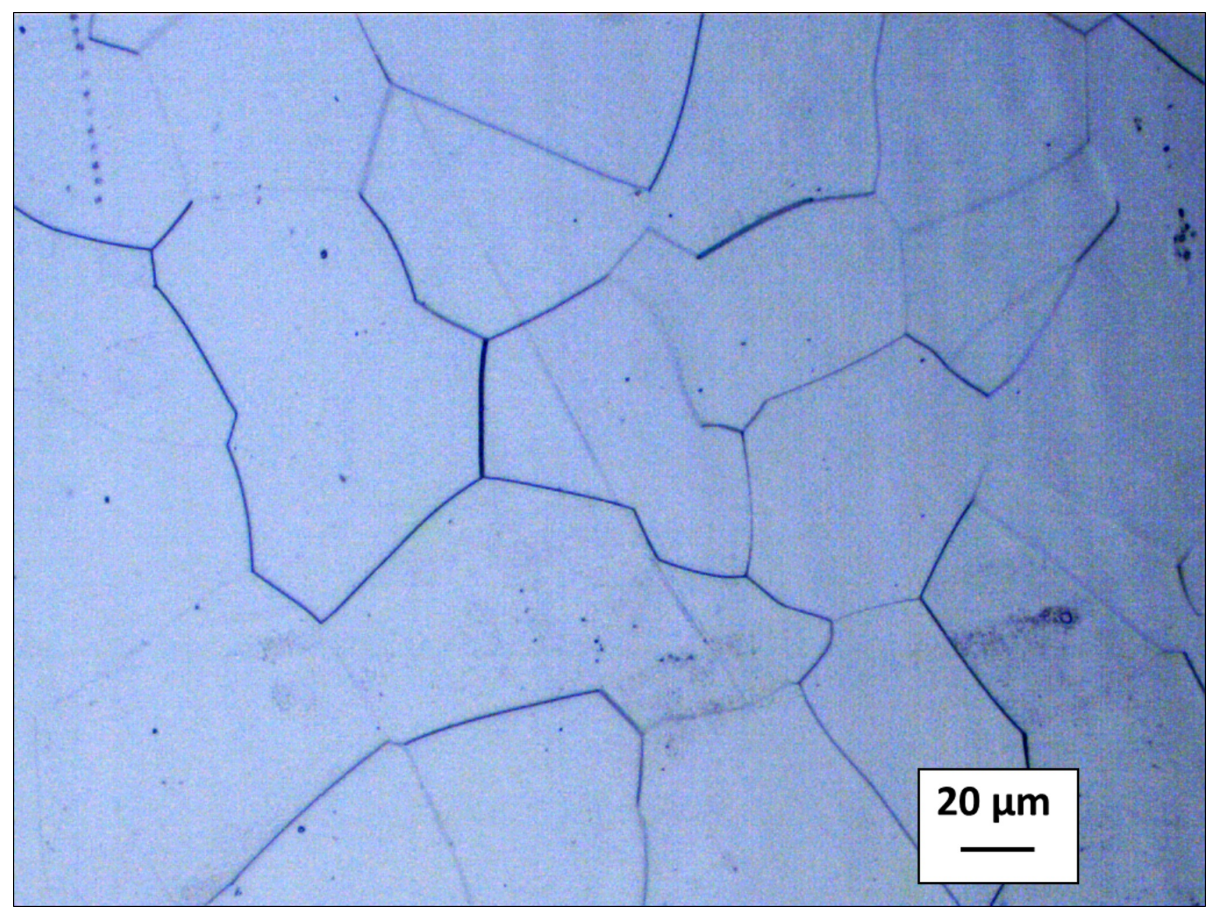

Fig. 2: Optical microstructure, showing equiaxed $\beta$-grains, of the Ti-Nb-Ta-O alloy in AR (annealed) condition

\subsection{Mirostructural evolution after surface treatment}

The XRD patterns of the material after being subjected to SMAT for different dwell times, i.e. 15 min., 30 min., 60 min. and 120 min., are shown in Fig.3. All the four patterns reveal the presence of $\beta$ phase only, with minor broadening observed in the 
patterns. The broadening of the peaks in the samples were estimated for all time durations. Fig. 4 displays the plot of Full Width at Half Maximum (FWHM) against duration of SMAT for the first three peaks, namely $\beta_{\{110\}}, \beta_{\{200\}}$ and $\beta_{\{112\}}$. An increasing trend in the FWHM values, as a function of dwell time, though not in similar fashion for all the peaks, can be visible from the Fig.4. There is also an indication of saturation in the FWHM values as the time reaches $120 \mathrm{~min}$. from 60 min., at least for $\beta_{\{110\}}$, $\beta_{\{200\}}$ peaks. The peak broadening in plastically deformed materials is manifested due to reduced crystallite size, and increased microstrain. The increase in the FWHM values as a function of time, clearly indicates the existence of plastic deformation on the surface. Peak broadening in SMAT-processed materials have previously been reported in literature and have been attributed to the formation of nanocrystallized grains as well as a significant increase in the dislocation densities after SMAT [15, 19]. In the present study, the fine features on the deformed SMAT surface could not be resolved with optical microscopy, and therefore wee characterized using scanning and transmission electron microscopy.

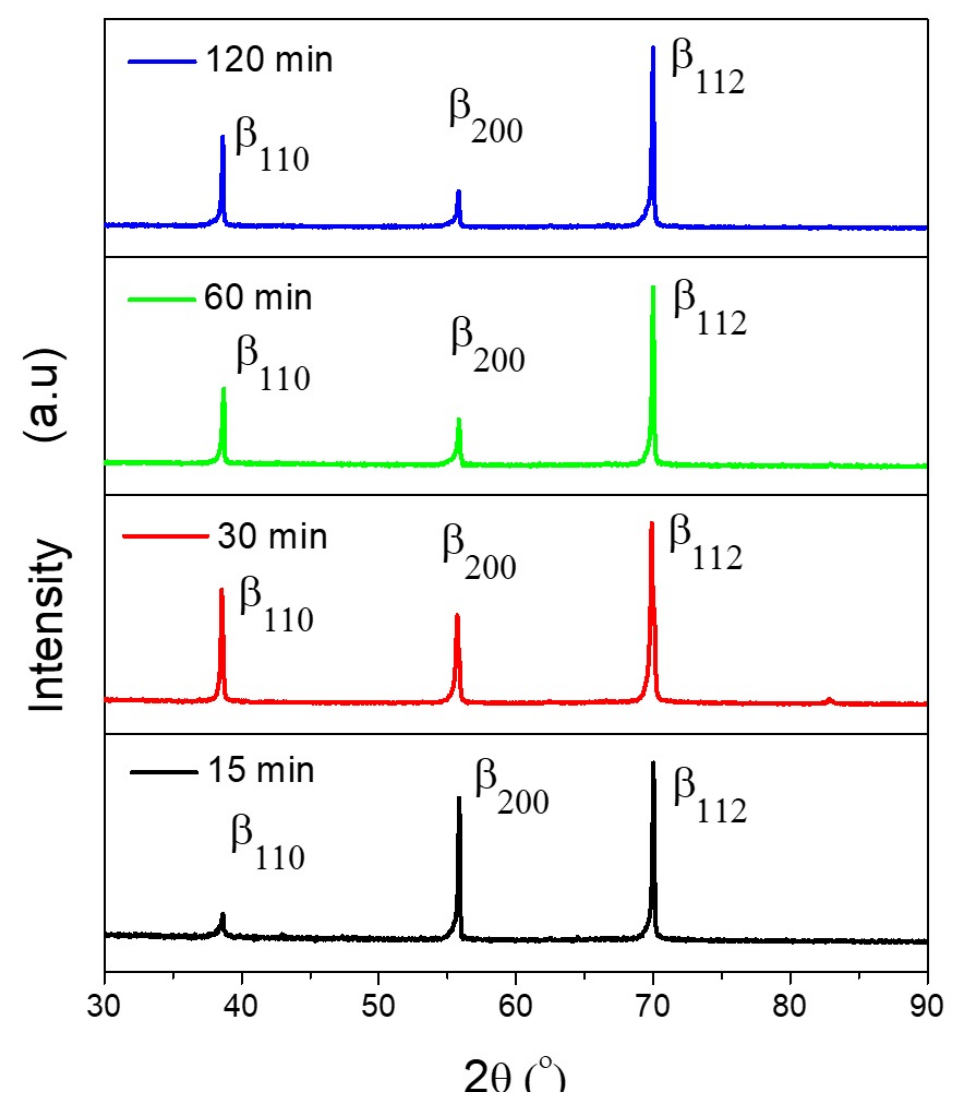

Fig. 3: X-ray diffraction patterns of the samples after different durations of SMAT 


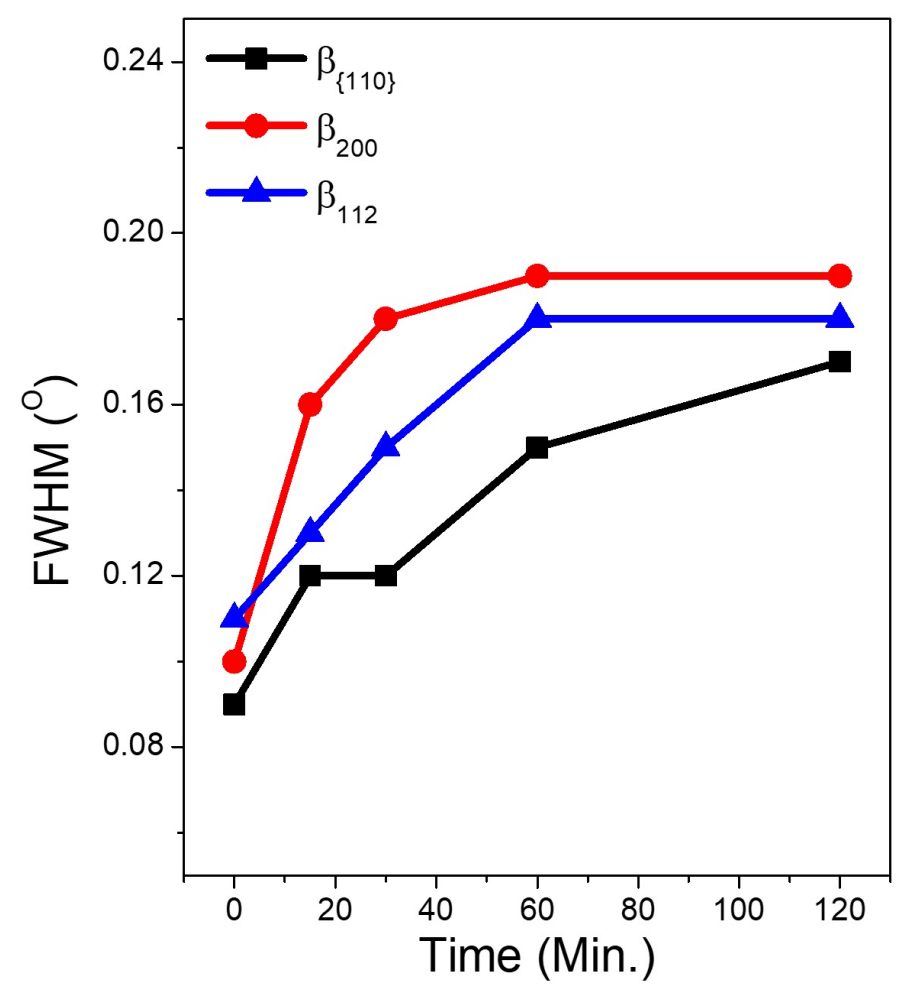

Fig. 4: Plot of Full Width at Half Maximum (FWHM) vs. duration of SMAT for different peaks

Figure 5 shows the cross-section SEM images of samples undergoing SMAT for 60 min. The region near the SMAT-affected side, marked by arrows, shows a contrast difference with the rest of the sample. The deformation-affected region has also been marked with the dashed lines. It also shows the presence of band-like features, as indicated by the blue arrow-lines. These could be perceived as microbands formed by SMAT. In metastable $\beta$-alloys, formation of microbands due to heavy plastic deformation have been reported in several literature $[20,21]$. Their formation during SMAT has been attributed to splitting of dense dislocation walls, which separate the cell blocks within the grains, leads to the formation of these microbands [17].

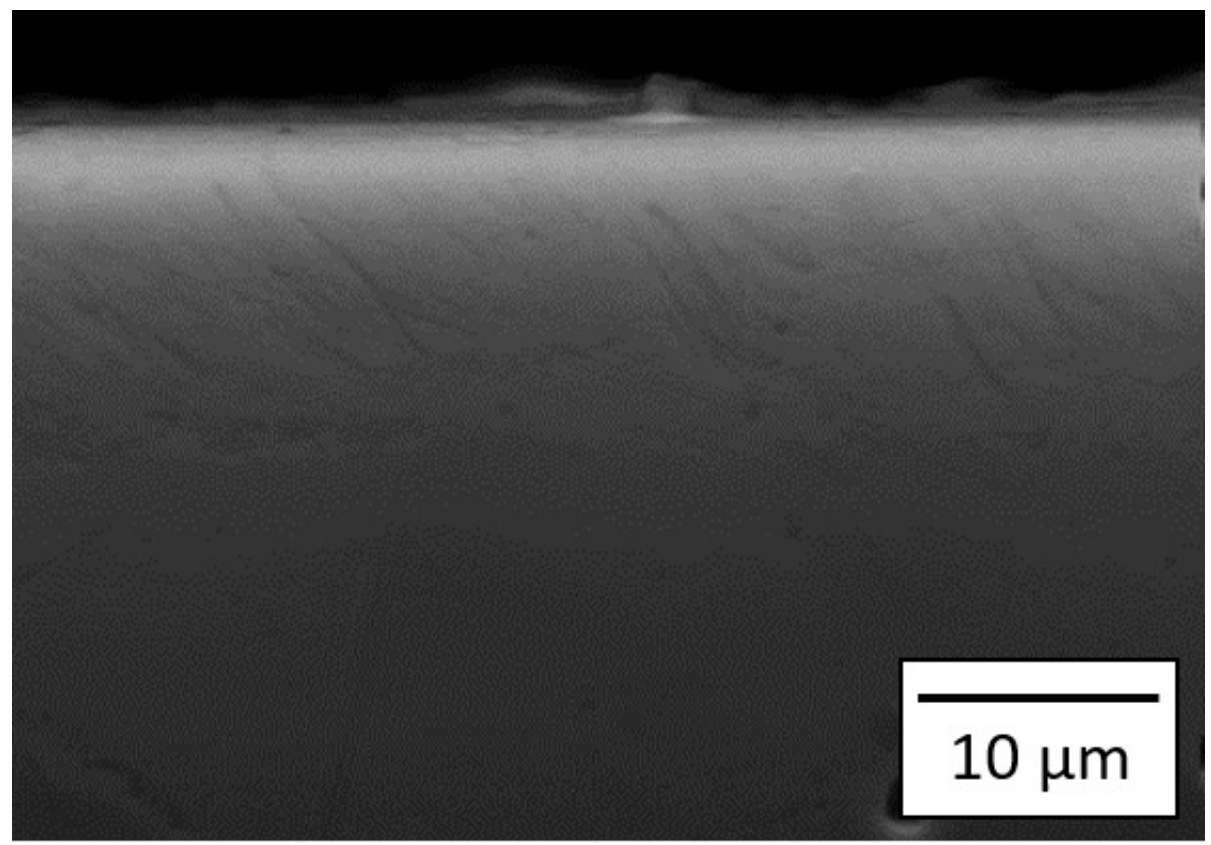


Fig. 5: SEM image of cross-section after surface treatment, showing SMAT-affected region near the edge, with the presence of microbands near the surface (the top horizontal edge of the sample is SMAT-processed surface)

\subsection{Effect of surface treatment on hardness}

The surface of AR sample shows a hardness of $290 \pm 7 \mathrm{HV}$ in the annealed condition, which is similar to that of the oxygen-added similar alloys, in annealed or $\beta$ solution treated condition. The surface hardness after SMAT for different dwell times is shown in Fig. 6. The hardness can be seen to increase as a function of dwell time up to $60 \mathrm{~min}$, beyond which no significant change was observed. The increase in the hardness after SMAT on the surface results from the deformation induced hardening mechanisms such as grain size strengthening and dislocation strengthening [15, 22]. The broadening in the XRD peaks, as discussed earlier, also confirm this. The microbands observed in the microstructures are also perceived to be a consequence of the heavy deformation process associated with SMAT. These microbands have been attributed to lead to the eventual formation of nanocrystallized grains on the surface. The microstructure does not reveal any other features distinguishing the deformed layer produced by SMAT, indicating that the microstructural features that distinguish the SMAT affected layer are fine enough.

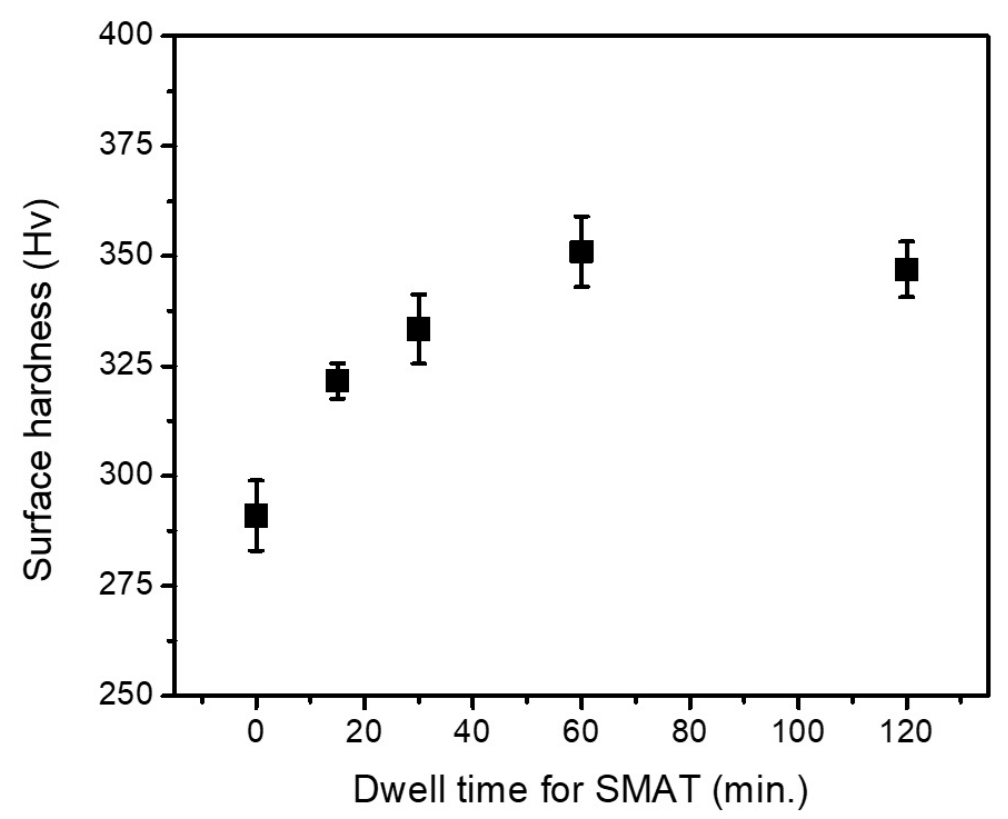

Fig. 6. Variation of surface hardness as a function of dwell time

\subsection{Corrosion Studies}

The corrosion current density $\left(\mathrm{I}_{\text {corr }}\right)$ and the corrosion potential $\left(\mathrm{E}_{\text {corr }}\right)$ values were measured by extrapolating the the cathodic and anodic regions of the Tafel plot. Average Icorr values of the AR and SMAT samples were found to be $47 \times 10^{-3} \mu \mathrm{A} / \mathrm{cm}^{2}$ and 11 $\times 10^{-3} \mu \mathrm{A} / \mathrm{cm}^{2}$, while the average $E_{\text {corr }}$ values were found to be $-0.28 \mathrm{~V}$ and $-0.12 \mathrm{~V}$. The reduction in $\mathrm{I}_{\text {corr }}$ values and increase in

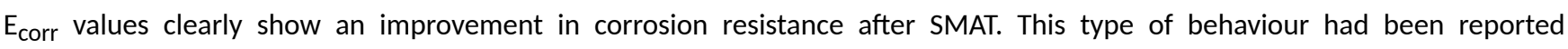
previously for SMAT-processed cp-Ti [15], Ti-6Al-4V alloy [16] and $\beta$ Ti-25Nb-3Mo-3Zr-2Sn alloy [18]. It has been proposed in the literature that severe plastic deformation methods like SMAT leads to generation of large number of lattice defects, as also seen from the microstructure of SMAT sample in the present alloy. The presence of these defects leads to formation of a much denser and more stable passive film on the surface of these samples. A similar mechanism can also be expected to act in the present case. Though the passive oxide film behaviour needs to be further studied in order to validate this, the Tafel plots indicate that SMAT is a favourable method in terms of electrochemical performance of the $\beta$-Ti-Nb-Ta-O alloy.

\section{Conclusions}


In the present study, the effects of surface mechanical attrition treatment on the mechanical and electrochemical behaviour of a Ti-Nb-Ta-O alloy have been studied. The surface treatment resulted in surface hardening and the time duration of SMAT was found to affect the surface hardness. The microstructure of SMAT materials exhibited the formation of micro-bands near SMATprocessed surface. This in effect resulted in hardening of the surface region. The corrosion behaviour also improved after SMAT possibly due to formation of more stable and dense passive oxide film by this process.

\section{Acknowledgement}

The authors acknowledge the funding by Science and Engineering Research Board (SERB), Department of Science and Technology, Govt. of India. We are grateful to Dr. Amit Bhattacharjee, Scientist and Head of Titanium Alloy Group, Defence Metallurgical Research Laboratory, Hyderabad India for many useful discussions.

\section{$\underline{\text { References }}$}

[1] D Kuroda, M Niinomi, M Morinaga, Y Kato, T Yashiro, Mater. Sci. Eng. A 243 (1998) 244.

[2] S Bahl, AS Krishnamurthy, S Suwas, K Chatterjee, Mater. Des. 126 (2017) 226.

[3] E Eisenbarth, D Velten, M Müller, R Thull, J Breme, Biomaterials 25 (2004) 5705.

[4] M Geetha, A Singh, R Asokamani, A Gogia, Prog. Mater. Sci. 54 (2009) 397.

[5] AK Mishra, J Davidson, Beta Titanium Alloys in the 1990's. (1993) 61.

[6] M Geetha, UK Mudali, A Gogia, R Asokamani, B Raj, Corros. Sci. 46 (2004) 877

[7] J Qazi, H Rack, B Marquardt, Jom 56 (2004) 49.

[8] Y.L. Hao, M. Niinomi, D. Kuroda, K. Fukunaga, Y.L. Zhou, R. Yang,

A. Suzuki, Metall.Mater. Trans. A 34 (2003) 1007.

[9] M Niinomi, M Nakai, J Hieda, Acta Biomater. 8 (2012) 3888.

[10] S S Acharya, AG Panicker, DV Laxmi, S Suwas, K Chatterjee, Mater. Des. 164 (2019) 107555.

[11] S S Acharya, P Gupta, K Chatterjee, S Suwas, Mater. Sci. Forum, Trans Tech Publ 941 (2018), 2465-2470.

[12] S. Acharya, S. Bahl, S. S. Dabas, S. Hassan, G. Vasanth, A.G. Panicker, M. Geetha, S. Suwas, K. Chatterjee, Mater. Sci. Eng. C, https://doi.org/10.1016/j.msec.2019.109755

[13] K Lu, J Lu, Mater. Sci. Eng. A 375 (2004), 38.

[14] S Bahl, S Suwas, T Ungar, K Chatterjee Acta Mater. 122 (2017) 138.

[15] S S Bahl, BT Aleti, S Suwas, K Chatterjee, Mater. Des. 144 (2018) 169.

[16] Z Z Deng, B Yin, W Li, J. Liu, J. Yang, T. Zheng, D. Zhang, H. Yu, X. Liu, J. Ma, Int J Nanomed 9 (2014) 5565.

[17] S S Bahl, P Shreyas, M Trishul, S Suwas, K Chatterjee, Nanoscale 7 (2015) 7704.

[18] R Huang, Y Han, Mater. Sci. Eng. C 33 (2013) 2353. 
[19] J Villegas, L Shaw, Acta Mater. 57 (2009) 5782.

[20] S Acharya, S Bahl, K Chatterjee, S Suwas, Materialia, 4 (2018) 20.

[21] B Sander, D Raabe Mater. Sci. Eng. A 479 (2008) 236.

[22] K Zhu, A Vassel, F Brisset, K Lu, J Lu, Acta Mater. 52 (2004) 4101.

[23] S Jelliti, C Richard, D Retraint, T Roland, M Chemkhi, C Demangel, Surf. Coat. Tech. 224 (2013) 82 